\title{
Editorial
}

\section{New Applications in Gas Geochemistry}

\author{
Francesco Italiano $\mathbb{D},{ }^{1}$ Andrzej Solecki $\mathbb{D},{ }^{2}$ Giovanni Martinelli $\mathbb{D}^{3},{ }^{3}$ Yunpeng Wang $\mathbb{D},{ }^{4}$ \\ and Guodong Zheng $\mathbb{1}^{5}$ \\ ${ }^{1}$ INGV, Palermo, Italy \\ ${ }^{2}$ Institute of Geological Sciences, University of Wrocław, Wrocław, Poland \\ ${ }^{3}$ ARPA Emilia-Romagna, Bologna, Italy \\ ${ }^{4}$ Guangzhou Institute of Geochemistry, Chinese Academy of Sciences, Guangzhou 510640, China \\ ${ }^{5}$ Key Laboratory of Petroleum Resources, Gansu Province, Northwest Institute of Eco-Environment and Resources, Chinese Academy \\ of Sciences, Lanzhou 730000, China
}

Correspondence should be addressed to Andrzej Solecki; andrzej.solecki@uwr.edu.pl

Received 21 February 2020; Accepted 21 February 2020; Published 2 July 2020

\begin{abstract}
Copyright (c) 2020 Francesco Italiano et al. This is an open access article distributed under the Creative Commons Attribution License, which permits unrestricted use, distribution, and reproduction in any medium, provided the original work is properly cited.
\end{abstract}

\begin{abstract}
Gases present in the Earth crust are important in various branches of human activities. Hydrocarbons are a significant energy resource, helium is applied in many high-tech instruments, and studies of crustal gas dynamics provide insight in the geodynamic processes and help monitor seismic and volcanic hazards. Quantitative analysis of methane and $\mathrm{CO}_{2}$ migration is important for climate change studies. Some of them are toxic $\left(\mathrm{H}_{2} \mathrm{~S}, \mathrm{CO}_{2}, \mathrm{CO}\right)$; radon is responsible for the major part of human radiation dose. The development of analytical techniques in gas geochemistry creates opportunities of applying this science in numerous fields. Noble gases, hydrocarbons, $\mathrm{CO}_{2}, \mathrm{~N}_{2}, \mathrm{H}_{2}, \mathrm{CO}$, and $\mathrm{Hg}$ vapor are measured by advanced methods in various environments and matrices including fluid inclusions. Following the "Geochemical Applications of Noble Gases"(2009), "Frontiers in Gas Geochemistry" (2013), and "Progress in the Application of Gas Geochemistry to Geothermal, Tectonic and Magmatic Studies" (2017) published as special issues of Chemical Geology and "Gas geochemistry: From conventional to unconventional domains" (2018) published as a special issue of Marine and Petroleum Geology, this volume continues the tradition of publishing papers reflecting the diversity in scope and application of gas geochemistry.
\end{abstract}

\section{Introduction}

The aim of this special issue was to collect contributions on the most recent advances in gas geochemistry. The current development of gas geochemical studies is connected not only with introducing advanced techniques combining among other: isotopic studies, gas chromatography, and mass spectrometry applied to hydrocarbons, carbon dioxide, rare gases, $\mathrm{H}_{2} \mathrm{~S}$, and $\mathrm{Hg}$ vapor, but the application of new geochemical, seismotectonic, and biogeochemical models as well. Gas geochemistry studies results not only in deeper insights in a broad range of geological processes but also in the quantification of the lithosphere, hydrosphere, and atmosphere interactions important both for hydrocarbon and geothermal resources, volcanic and seismic risk, human health, and climate change.
This volume contains a significant number of papers delivered by participants of the 14th International Conference on Gas Geochemistry (ICGG) held in Wrocław-Świeradów, Poland, 24-28 September 2017. The list of contributors has been supplemented by numerous authors who did not participate in the 14th ICGG, whose primary topic was "Gases in the Earth crust, benefits and hazards". However, all delivered papers stay in line with the primary topic focusing not only on gases as a tool of geochemical, seismotectonic, and petrogenetic studies but also on the environmental risk management.

\section{Themes}

The 22 papers of this volume can be grouped into 4 general themes. Hydrocarbon gases are the dominant topic and this 
volume contains 10 papers aimed at understanding their origin, relationship with geodynamic, and biochemical processes both in oil fields and natural seepages as well.

Zhifu Wei et al. (in this issue) compared the isotopic composition of gas obtained by closed-system FischerTropsch synthesis with a deep Songliao Basin gas which is similar to thermogenic gas and has a trend of a transition to oceanic hydrothermal system abiogenic gas.

Cancan Yan et al. (in this issue) proposed a new technique, syringe solid phase extraction (SSPE), for the enrichment of trace hydrocarbon compounds for isotope analysis (CSIA) with a gas chromatograph (GC) interfaced to an isotope ratio mass spectrometry (IRMS).

Pengfei Di et al. (in this issue) quantified the dissolved methane and its air-sea flux from hydrocarbon seeps from the seafloor to the coastal ocean near the Lingtou Promontory, South China Sea.

Dan Liu (in this issue) studied Paleozoic gases in the southern Ordos Basin, China, with partial or complete isotopic reversals, as examples of isotopic fractionation in over mature coal-derived gases.

Rui Deng et al. (in this issue) studied the impacts of temperature and pressure histories and gas washing on the formation of the condensate gas reservoirs and evolution of the fluid phase and its features in the Tazhong Uplift area in the Tarim Basin of China.

F. Gal et al. (in this issue) investigated hydrocarbon gas seeps located in the French Subalpine Chains in zones of outcropping Jurassic black shales.

Yanping Zhang et al. (in this issue) studied the transfer of carbon from sediments to the water column in the South China Sea by chemosynthetic biotainhabited surface sediments and found that the biogeochemical rates in the northern SCS are generally lower than those in active continental margins and special environments (e.g., the Black Sea), but are comparable with those in passive continental margins.

Xiaobo Wang et al. (in this issue) studied coal-formed gases of the Kuche Depression. Accompanying rare gases in the Kuche Depression were found to be of typical crustal genesis-derived from the radioactive decay of crustal elements.

Junxi Feng et al. (in this issue) studied active cold seeps of Haima that were recently discovered on the northwestern slope of the South China Sea. The analysis of three piston cores from an area characterized by bottom simulating reflectors to the west of Haima suggests that methane seepage probably has persisted at least hundreds to thousands of years with changing methane fluxes.

Xiangxian $\mathrm{Ma}$ et al. (in this issue) analyzed mineral and/or chemical compositions and sulfur and carbon isotopes of natural gas, formation water, and rocks of volcanic rock reservoirs in the Niudong area of the Santanghu Oilfields to explain the occurrence and origin of hydrogen sulfide $\left(\mathrm{H}_{2} \mathrm{~S}\right)$. The $\delta^{34} \mathrm{~S}$ values of on-well $\mathrm{H}_{2} \mathrm{~S}$ samples varied in a range of $9.2 \%$ to $20.5 \%$, indicating thermochemical sulfate reduction (TSR) and/or thermal decomposition of organic sulfur-bearing compounds (TDS).

Gas geochemistry of volcanic fields was the second dominant topic and this volume contains 7 papers aimed at a broad spectrum of problems starting from understanding petrogenetic processes via the mechanism of gaseous exhalation to its influence upon plant cover.

Mingjie Zhang et al. (in this issue) measured C, He, Ne, and $\mathrm{Ar}$ isotopic compositions of volatiles from magmatic minerals in the Podong ultramafic intrusion. The $\delta^{13} \mathrm{C}$ of $\mathrm{CO}_{2}$ and $\mathrm{CH}_{4}$ suggested the magmatic volatile of the mantle mixed with the volatiles of thermogenic and crustal origins. Subduction and devolatilization of altered oceanic crust could be the best mechanism that transported large proportions of air-saturated fluid and crustal components into the mantle source.

A. L. Gagliano et al. (in this issue) performed an extensive survey on $\mathrm{Hg}$ concentrations in different matrices (fumarolic fluids, atmosphere, soils, and plants) at the Lakki Plain, Nisyros Island (Greece). The positive correlation with both $\mathrm{CO}_{2}$ and $\mathrm{H}_{2} \mathrm{~S}$ in air highlighted the importance of hydrothermal gases as carrier for gaseous elemental mercury. On the other hand, soil $\mathrm{Hg}$ concentrations showed no significant correlations with $\mathrm{CO}_{2}$ and $\mathrm{H}_{2} \mathrm{~S}$ in the soil gases, whereas it showed a positive correlation with the total $\mathrm{S}$ content and an inverse one with the soil $\mathrm{pH}$, evidencing the complexity of the processes involving $\mathrm{Hg}$ carried by hydrothermal gases while passing through the soil.

F. Italiano et al. (in this issue) carried out geochemical investigations on submarine hydrothermal fluids vented offshore the Pontine Islands (Tyrrhenian Sea) and revealed the existence of gas vents to the West of Zannone Island and Southwest of Ventotene Island. The geochemical features of the $\mathrm{CO}_{2}$-rich gas samples show a clear mantle-derived signature and indicate that cooling Middle Pleistocene magmas are of thermal energy high enough to form an efficient hydrothermal system.

M. A. Amonte et al. (in this issue) performed the first integrated heat flow, $\mathrm{CO}_{2}$, and ${ }^{3} \mathrm{He}$ emission survey across $0.5 \mathrm{~km}^{2}$ of the summit cone and crater of Teide volcano, Tenerife, Canary Islands, Spain. The calculation of the ${ }^{3} \mathrm{He} /$ heat ratio for the first time in this volcanic system supports the presence of an important mantle source for the degassing of Teide volcano.

H. Pfanz et al. (in this issue) studied the relationship between postvolcanic soil degassing and vegetation during spring season in mofette at the banks of the Laacher See, Eifel Mountains. Plant coverage and the number of species decreased significantly in high $\mathrm{CO}_{2}$ areas. One plant species (marsh sedge, Carex acutiformis) proved to be highly mofettophilic and strictly grew on $\mathrm{CO}_{2}$ degassing sites.

$\mathrm{H}$. Kämpf et al. (in this issue) measured gas flux measurements of cold, mantle-derived $\mathrm{CO}_{2}$ release at the Bublák mofette field located inside presently seismically active Počátky Plesná fault zone (PPFZ) (Czech republic) and found that en-echelon faults inside of the PPFZ act as fluid channels to depth $\left(\mathrm{CO}_{2}\right.$ conduits).

Wenbin Zhao et al. (in this issue) studied bubbling springs and diffuse degassing from soils of the Wudalianchi monogenetic volcanic field in a major continental rift system in NE China. Chemical compositions and C-He isotope analyses revealed that the cold spring gases might originate from the enriched upper mantle, which resulted from the mixing between slab materials (subducted organic sediments and 
carbonates) in the mantle transition zone and the ambient depleted mantle. Their results suggest that the $\mathrm{CO}_{2}$ degassing activities become weaker from early to late in Quaternary.

Gas geochemistry applied to seismic zones studies was the third dominant topic and this volume contains 4 papers aimed at understanding gas exhalation in active seismic zones with their possible application as precursor signals.

Nagaraju Podugu et al. (in this issue) studied helium isotope ratios of $3 \mathrm{~km}$ deep research borehole KFD1 in the Koyna reservoir-triggered seismicity region, Western India. Air-corrected helium isotope ratios indicate that helium is a mixture of atmospheric and crustal radiogenic components without mantle contribution.

Ching-Chou Fu et al. (in this issue) described significant increases of soil radon concentrations followed by the increase in gamma rays a few days to a few weeks before earthquakes that occurred in northeastern Taiwan, where the subduction of the Philippine Sea Plate PSP beneath the Eurasian Plate occurs.

F. Italiano et al. (in this issue) studied the southernmost portion of the Apennine chain (Nebrodi-Peloritani Mountains, Sicily, Italy) and revealed a close connection between the tectonic setting and the regional degassing of $\mathrm{CO}_{2}$ dominated volatiles. Their study yields better insight into the evolution of seismogenesis, considering the fault ruptures as the final stage of a seismic cycle.

K. Daskalopoulou et al. (in this issue) studied natural gas exhalations at the island of Kos. Changes in the degassing areas and significant variations in the geochemical parameters of the released gases were observed both before and after the seismic event; however, no coherent model explaining those changes was obtained.

We also have a fourth domain in environmental and healthy effect of dangerous gases, although there is only one single paper presented: Dương Nguyễn-Thuỳ et al. (in this issue) described thoron's (220Rn) contribution to aradiation exposure and found it significant input in radiation exposure in traditional northern Vietnamese mud house with bare surfaces of dry porous soil dwellings.

\section{Concluding Remarks}

Since the very beginning, the ICGG has been the forum where we exchange ideas on gas geochemistry. Originally dominated by radon topics, it evolved towards the broad spectrum of gas geochemistry problems. The ICGG 14th chose Świeradów town in Lower Silesia (Poland) due to a historical record of almost 450 years of balneotherapy, with radon as a main curative factor identified in the 20th century. The ICGG 14th commenced in Wroclaw-the capital of the Lower Silesia Province with choir concert in the Oratorium Marianum-baroque music hall in the main building of the University of Wroclaw. This meeting attracted around 60 delegates performing 36 oral and 20 poster presentations.

During the ending field trip (28-30.09.2017), the participants visited Carpathians Mts. with stop at the Bóbrka oil mine opened in 1854 and still operating as the Ignacy Łukasiewicz Museum of Oil and Gas Industry, geothermal spas of the Podhale region and the Salt Mine of Wieliczka operating since 13th century.

Proceedings of the meetings are traditionally published as Special Issues in peer-reviewed journals, as in the present case. ICGG continues to attract widespread participation-in the form of oral and poster presentations-from a diverse international audience. We look forward to the 15th ICGG scheduled to be held in Italy in September, 2019.

\section{Conflicts of Interest}

We confirm that the Lead Guest Editor and the other Guest Editors have no conflict of interest.

\section{Acknowledgments}

This special issue is derived directly from the 14th ICGG held in Wrocław-Świeradów, Poland in September 2017. We would like to thank Giovanni Martinelli for his inspiration to perform 14th ICGG in Poland. We thank all who contributed to the success of the meeting-keynote speakers, oral/poster presenters, and other registrants. We would like to thank the co-organizers: University of Wroclaw and Wroclaw University of Science and Technology for their organizational and financial support. We also would like to thank Wrocławskie Centrum Akademickie and EXALO Grupa PGNiG for their sponsorship. The editors specially thank academic editors: Andrea Brogi, Andrew H. Manning, Andri Stefansson, and Julien Bourdet for their contribution to this special issue. The papers in this volume were scrutinized by a cadre of reviewers, who cannot be mentioned one by one but they all deserve sincere thanks.

Francesco Italiano Andrzej Solecki Giovanni Martinelli Yunpeng Wang Guodong Zheng 